\title{
An Analysis of Perception of TNAU Agritech Portal and Utilization Pattern of the Portal among the Students in Coimbatore
}

\author{
M. Deepika* and A. Jeevapriya \\ Department of Agricultural Extension, Tamil Nadu Agricultural University, \\ Coimbatore, India \\ *Corresponding author
}

\section{A B S T R A C T}

\section{Keywords}

Agritech Portal, Information communication tools

\section{Article Info}

\section{Accepted:}

15 December 2020

Available Online:

10 January 2021
New media tools or information communication tools are evolving for the benefit of people and students who are in seek of information. Increase in Agricultural production is constrained by limited land and water availability. Further growth can be achieved only through increase in yield. This gap can be bridged by an effective extension system. Decreasing fund allocation, limited capacities of extension staff, large number of farm families, poor reach to marginal and small farmers, low literacy rate among the farming community are all limitations of the present extension system. In this context - e-extension centre of Tamil Nadu Agricultural University has established a unique portal named TNAU Agritech Portal. The results revealed that 53.00 per cent of respondents had medium level of perception of the portal and equal percentage of respondents fell under both low and high levels (36.66\%) utilization pattern of the portal. Majority of the respondents reported web irresponsiveness of portal as a primary constraint in accessing the portal and they also suggested that ICAR question bank, global level market trends and more number of pictures and videos with high clarity can be included.

\section{Introduction}

Use of information and communication technology has changed our conventional way of thinking and proposes the need to rethink education in terms of a more current context. It can be used to find, develop, analyse and present information as well as to model situation and solve problems. A website is a collection of all the facts and information in different pages that are included or contained under a domain name. A website contains texts, images and videos. A portal is defined in the dictionary as a gateway or an entry point to a grand entrance. Thus a web portal, in addition to being a website, also acts as a gateway to the internet, Sujeetha. T.N.(2016). In such a context Tamil Nadu Agricultural University launched a portal named as TNAU Agritech Portal for providing information related to Agriculture and its allied sectors. It was launched in the year 2008-09. It is the first product of e-extension center. This project is sponsored by National Agricultural Development Project. It contains more than 9 lakh pages of information with nearly 30005000 of visitors per day followed by $1200-$ 2500 of new visitors per day. This portal has 
nearly 75 major sections with 10 major line departments viz., Agriculture, Horticulture, Agricultural Engineering, Fisheries, Sericulture, Agricultural marketing, Animal Husbandry, Organic Farming, Seed Certification and Forestry. It also includes success stories of farmers, frequent updates, market information, schemes and services etc.

To study the utilization pattern of the portal among the students.

To find out the perception of the portal among the students.

\section{Materials and Methods}

Ex post facto research design was used for this study. Totally 30 respondents were selected including Under Graduate, Post Graduate and Doctoral students of Tamil Nadu Agricultural University (TNAU) by using purposive sampling method.

Well structured questionnaire was used for data collection. Percentage analysis was used for the meaningful interpretation of the results.

\section{Results and Discussion}

The data collected from the students regarding their profile, utilization pattern, perception and constraints were analysed and presented in the following tables.

\section{Profile of the respondents}

The following table depicts the profile of the respondents.

From the above table1, it could be inferred that, majority of the respondents 66.66 per cent were female with Doctoral education $(50 \%)$, having low level of electronic gadgets possession $(53.33 \%)$ and with high portal credibility $(46.66 \%)$.

\section{Students Perception about the portal}

The following table depicts the perception of the portal among the respondents.

From the above table it is inferred that 40.00 per cent are highly satisfied with background colour had appearance followed by 36.60 per cent of the respondents with attractiveness of homepage and 16.66 per cent of respondents with font size.

It is found that 70.00 per cent of the respondents are satisfied with font size followed by 60.00 of the respondents with attractiveness of homepage, background colour and appearance, reading ease of message content and accuracy of the subject.

It is revealed that 20.00 of the respondents are not satisfied with the practical utility of the subject followed by 16.66 per cent with accuracy of the subject and $3.33 \%$ of the respondents are not satisfied with homepage.

\section{Overall perception of the portal}

The following table depicts the overall perception of the portal by the respondents

From the above table, 53.33 per cent have medium level of perception followed by 46.66 per cent of respondents have low level of perception.

\section{Utilization pattern of the respondents}

The following table shows that the usage frequency of Agritech Portal among the respondents

From the above table 4, it is inferred that 43.33 per cent regularly visits agriculture, agricultural information's followed by 33.33 
per cent visited home page and 3.33 per cent of respondents visited success stories, farmers association, sericulture and forestry regularly.

It is found that 66.66 per cent occasionally visits the homepage followed by 50.00 per cent visited farmers association, frequent updates, success stories and horticulture and
6.66 per cent of respondents visited fishery occasionally.

It is inferred that 93.33 per cent of the respondents rarely visited fishery page followed by 76.66 per cent visited sericulture page and 16.66 per cent visited technologies and agriculture information rarely.

Table. 1 Profile of the respondents $n=30$

\begin{tabular}{|c|c|c|c|c|}
\hline S.No. & Profile & Category & \multicolumn{2}{|c|}{ Users } \\
\cline { 4 - 5 } & & & Frequency & Percentage \\
\hline $\mathbf{1}$ & Gender & Male & 10 & 33.33 \\
& & Female & 20 & 66.66 \\
\hline $\mathbf{2}$ & Educational status & Under graduate & 3 & 10 \\
& & Post graduate & 12 & 40 \\
& & Doctoral & 15 & 50 \\
\hline $\mathbf{3}$ & Possession of & Low & 16 & 53.33 \\
& electronic gadgets & Medium & 14 & 46.66 \\
\hline $\mathbf{4}$ & Portal credibity & High & 10 & 33.33 \\
& & Low & 6 & 10 \\
& & Medium & 14 & 46.66 \\
\hline
\end{tabular}

Table.2 Distribution of the respondents based on their perception of the portal $n=30$

\begin{tabular}{|c|c|c|c|c|c|c|c|}
\hline \multirow[t]{2}{*}{ S.No. } & \multirow[t]{2}{*}{ Items } & \multicolumn{2}{|c|}{ Highly satisfied } & \multicolumn{2}{|l|}{ Satisfied } & \multicolumn{2}{|c|}{ Not satisfied } \\
\hline & & $\begin{array}{l}\text { Freque- } \\
\text { ncy }\end{array}$ & $\begin{array}{l}\text { Percenta } \\
\text {-ge }\end{array}$ & $\begin{array}{l}\text { Frequen } \\
\text {-cy }\end{array}$ & $\begin{array}{l}\text { Percen } \\
\text {-tage }\end{array}$ & Frequency & $\begin{array}{l}\text { Perce- } \\
\text { ntage }\end{array}$ \\
\hline 1 & $\begin{array}{l}\text { Attractiveness } \\
\text { Of homepage designs }\end{array}$ & 11 & 36.6 & 18 & 60 & 1 & 3.33 \\
\hline 2 & $\begin{array}{l}\text { Background } \\
\text { Colour \& appearance }\end{array}$ & 12 & 40 & 18 & 60 & 0 & 0.00 \\
\hline 3 & Font size & 5 & 16.66 & 21 & 70 & 4 & 13.33 \\
\hline \multirow[t]{4}{*}{4} & Message component & & & & & & \\
\hline & Reading ease & 8 & 26.66 & 18 & 60 & 4 & 13.33 \\
\hline & Accuracy of the subject & 7 & 23.33 & 18 & 60 & 5 & 16.66 \\
\hline & $\begin{array}{l}\begin{array}{l}\text { Practical utility of } \\
\text { subject }\end{array} \\
\end{array}$ & 7 & 23.33 & 17 & 56.66 & 6 & 20 \\
\hline
\end{tabular}


Table.3 Distribution of respondents based on overall perception of the portal $n=30$

\begin{tabular}{|l|l|l|l|}
\hline S.No & Category & Frequency & Percentage \\
\hline $\mathbf{1}$ & Low & 14 & 46.66 \\
\hline $\mathbf{2}$ & Medium & 16 & 53.33 \\
\hline $\mathbf{3}$ & High & 0 & 0.00 \\
\hline & Total & 30 & 100 \\
\hline
\end{tabular}

Table.4 Distribution of respondents based on their utilization pattern of portal $n=30$

\begin{tabular}{|c|c|c|c|c|c|c|c|}
\hline \multirow[t]{3}{*}{ S.No } & \multirow[t]{3}{*}{ Portal Content } & \multicolumn{6}{|c|}{ Frequency of Use } \\
\hline & & \multicolumn{2}{|l|}{ Regularly } & \multicolumn{2}{|c|}{ Occassionally } & \multicolumn{2}{|l|}{ Rarely } \\
\hline & & Frequency & Per centage & Frequency & Per cent & Frequency & $\begin{array}{l}\text { Per } \\
\text { centage }\end{array}$ \\
\hline 1 & Homepage & 10 & 33.33 & 20 & 66.66 & 0 & 0.00 \\
\hline 2 & Success stories & 1 & 3.33 & 15 & 50 & 14 & 46.66 \\
\hline 3 & $\begin{array}{l}\text { Farmers } \\
\text { Association }\end{array}$ & 1 & 3.33 & 15 & 50 & 14 & 46.66 \\
\hline 4 & Technologies & 7 & 23.33 & 18 & 60 & 5 & 16.66 \\
\hline 5 & $\begin{array}{l}\text { Schemes \& } \\
\text { Services }\end{array}$ & 9 & 30 & 12 & 40 & 9 & 30 \\
\hline 6 & Agri informations & 13 & 43.33 & 12 & 40 & 5 & 16.66 \\
\hline \multirow[t]{2}{*}{7} & Frequent updates & 9 & 30 & 15 & 50 & 6 & 20 \\
\hline & DEPARTMENTS & & & & & & \\
\hline 1 & Agriculture & 13 & 43.33 & 10 & 33.33 & 7 & 23.33 \\
\hline 2 & Horticulture & 4 & 13.33 & 15 & 50 & 11 & 36.66 \\
\hline 3 & $\begin{array}{l}\text { Agricultural } \\
\text { marketing }\end{array}$ & 5 & 16.66 & 10 & 33.33 & 15 & 50 \\
\hline 4 & $\begin{array}{l}\text { Agricultural } \\
\text { engineering }\end{array}$ & 4 & 13.33 & 5 & 16.66 & 21 & 70 \\
\hline 5 & Organic farming & 3 & 10 & 10 & 33.33 & 17 & 56.66 \\
\hline 6 & Sericulture & 1 & 3.33 & 6 & 20 & 23 & 76.66 \\
\hline 7 & Forestry & 1 & 3.33 & 7 & 23.33 & 22 & 73.33 \\
\hline 8 & Seed certification & 2 & 6.66 & 7 & 23.35 & 21 & 70 \\
\hline 9 & Fishery & 0 & 0.00 & 2 & 6.66 & 28 & 93.33 \\
\hline
\end{tabular}

Table.5 Distribution of respondents based on overall utilization pattern of the $n=30$

\begin{tabular}{|l|l|l|l|}
\hline S.No & Category & Frequency & Percentage \\
\hline $\mathbf{1}$ & Low & 11 & 36.66 \\
\hline $\mathbf{2}$ & Medium & 8 & 26.66 \\
\hline $\mathbf{3}$ & High & 11 & 36.66 \\
\hline & Total & 30 & 100 \\
\hline
\end{tabular}


Table.6 Distribution of respondents based on the constraints faced by the respondents in accessing the portal $n=30$

\begin{tabular}{|l|l|c|c|}
\hline S.no & Category & Frequency & Percentage \\
\hline $\mathbf{1}$ & Web irresponsive & 24 & 80 \\
\hline $\mathbf{2}$ & Low clarity of photos and videos & 18 & 60 \\
\hline $\mathbf{3}$ & Limited informations & 6 & 20 \\
\hline $\mathbf{4}$ & Lack of authenticity & 12 & 40 \\
\hline
\end{tabular}

\section{Overall Utilization Pattern of the Portal}

The table 5 shows the overall utilization pattern of the portal by the students of TNAU.

Table 5 revealed that 36.66 per cent of respondents fall under high level of utilization category followed by 26.66 per cent under medium level and 36.66 per cent have low level of utilization.

\section{Constraints faced by the respondents}

The following table depicts the constraints encountered by the respondents. The above table it is inferred that 80.00 per cent of respondents reported the web irresponsiveness as the major constraint.

In conclusion the study reveals that 46.66 per cent of the respondents had low level of credibility towards the portal hence, to improve the credibility the contents may include the source of collecting the contents for the portal. The font size of the contents was perceived to be less by more than onetenth of the students. Hence it is suggested to include a customized option for viewing the contents of the portal according to the preferred font size by the users of the portal. The portal can be converted into web responsive as majority of the respondents wish to access the portal through their android mobile. Academic related content such as ICAR question bank can be added under TNAU website for the students.

\section{Acknowledgement}

I sincerely thank my Professor and my seniors in helping me to complete my research.

\section{References}

agritech.tnau.ac.in

Sujeetha.T.N. and Karthikeyan.C. (2016) Design, Features and Utility of TNAU Agritech Portal. Advances in Life Sciences.

Yoga.J and Karthikeyan.C (2016) A Study On Knowledge Management Process In Agritech Portal And Seeking Suggestions For Content Management. International Journal of Mathematics and Computer Applications Research.

\section{How to cite this article:}

Deepika, M. and Jeevapriya, A. 2021. An Analysis of Perception of TNAU Agritech Portal and Utilization Pattern of the Portal among the Students in Coimbatore. Int.J.Curr.Microbiol.App.Sci. 10(01): 2465-2469. doi: https://doi.org/10.20546/ijcmas.2021.1001.285 